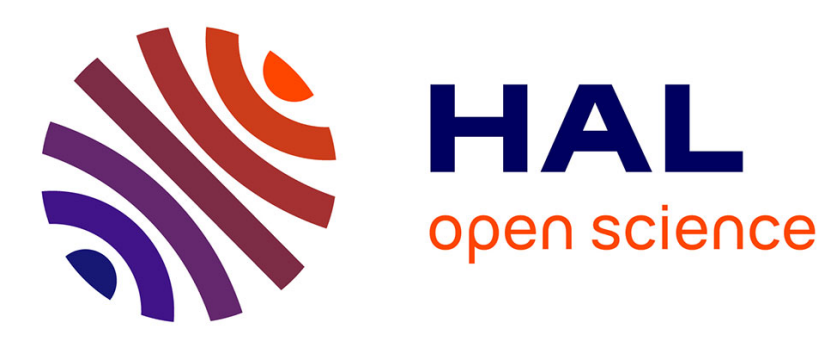

\title{
Type Synthesis of Two DOF Hybrid Translational Parallel Manipulators
}

Latifah Nurahmi, Stéphane Caro, Sébastien Briot

\section{To cite this version:}

Latifah Nurahmi, Stéphane Caro, Sébastien Briot. Type Synthesis of Two DOF Hybrid Translational Parallel Manipulators. The 2nd International Conference on Mechanical Engineering (ICOME 2015), Sep 2015, Patra Jasa, Bali, Indonesia. hal-02947200

\section{HAL Id: hal-02947200 https://hal.science/hal-02947200}

Submitted on 23 Sep 2020

HAL is a multi-disciplinary open access archive for the deposit and dissemination of scientific research documents, whether they are published or not. The documents may come from teaching and research institutions in France or abroad, or from public or private research centers.
L'archive ouverte pluridisciplinaire HAL, est destinée au dépôt et à la diffusion de documents scientifiques de niveau recherche, publiés ou non, émanant des établissements d'enseignement et de recherche français ou étrangers, des laboratoires publics ou privés. 


\title{
Type Synthesis of Two DOF Hybrid Translational Parallel Manipulators
}

\author{
Latifah Nurahmi, Stéphane Caro and Sébastien Briot \\ Institut de Recherche en Communications et Cybernétique de Nantes, France
}

Emails: \{latifah.nurahmi,stephane.caro,sebastien.briot\}@irccyn.ec-nantes.fr

Keywords: type synthesis, screw theory, hybrid legs, and parallel manipulators.

\begin{abstract}
This paper introduces a methodology for the type synthesis of two degree-of-freedom hybrid translational manipulators with identical legs. The type synthesis method is based upon the screw theory. Three types of two degree-of-freedom hybrid translational manipulators with identical legs are identified based upon their wrench decomposition. Each leg of the manipulators is composed of a proximal module and a distal module mounted in series. The assembly conditions and the validity of the actuation scheme are also defined. Eventually, some novel two degree-offreedom hybrid translational manipulators are synthesized with the proposed procedure.
\end{abstract}

\section{Introduction.}

At the conceptual design stage of manipulator architectures, the idea is to construct several design alternatives by following a systematic approach. However, the information at this stage is usually qualitative and not quantitative, which makes the design process quite difficult and challenging. A manipulator is a mechanical system that aims at manipulating objects. For simple task such as pick-and-place operations, the two degrees-of-freedom (2-dof) parallel manipulators are sufficient. Several 2-dof translational parallel manipulators (TPMs) are composed of a planar architecture that yields their stiffness quite low along the normal to the plane of motion [1]. Moreover, those manipulators are usually not composed of identical legs.

In order to increase the stiffness properties of the 2-dof TPM, Company et al. from LIRMM France have proposed a manipulator architecture named Par2 [2]. This architecture has the particularity to be spatial instead of planar and hence is stiffer along the normal to the plane of motion. Two legs amongst the four legs of the manipulator are linked to each other with a rigid belt in order to constrain the rotation of the moving platform. As a consequence, it leads to a robot with poor accuracy. To avoid the design problems of the Par2, a new robot with spatial architecture and two legs has been proposed: the IRSBot-2 [3]. Each leg of the IRSBot-2 is hybrid, i.e. it is composed of a proximal module and a distal module mounted in series, each module containing two kinematic chains. This manipulator has exhibited interesting stiffness properties. Therefore, it is of interest to focus on the type synthesis of 2-dof TPMs by considering architectures with hybrid legs.

In this paper, the general approach for the type synthesis of manipulators is presented to design the 2-dof hybrid TPMs with two identical legs. Each leg is composed of a proximal module and a distal module mounted in series as shown in Fig. 1. The proximal module is linked to the base while the distal module is linked to the moving platform. Those modules contain two kinematic chains mounted in parallel. These kinematic chains are called subleg.

The approach is developed based on the screw theory $[4,5,6]$ and it is decomposed into five steps: (i) Classification of the leg-constraint wrench system; (ii) Decomposition of the constraint wrench system of a proximal module and a distal module; (iii) Type synthesis of the sublegs; (iv) Assembly of the sublegs and legs; (v) Selection of the actuated joints.

For the type synthesis explained hereafter, the following notations are used throughout the paper: the twist system $\mathcal{T}$ is composed of zero-pitch twist $\xi_{0}$ and infinite-pitch twist $\xi_{\infty}$; the constraint wrench system $\mathcal{W}$ is composed of zero-pitch wrench $\zeta_{0}$ and infinite-pitch wrench $\zeta_{\infty}$. The $\xi$ and $\zeta$ are represented by cone arrow and pyramid arrow, respectively. The $c, c^{i}, c^{j}$, and $c^{k}$ are the order of the constraint wrench systems of the manipulator, the leg $i$, the module $j$, and the subleg $k$. The $\mathrm{R}$ and $\mathrm{P}$ denote revolute and prismatic joints, respectively; while ()$_{\mathrm{S}},()_{\mathrm{E}}$ and ()$_{\mathrm{C}}$ denote the kinematic joints that produce spherical, planar and cylindrical motions, respectively. 


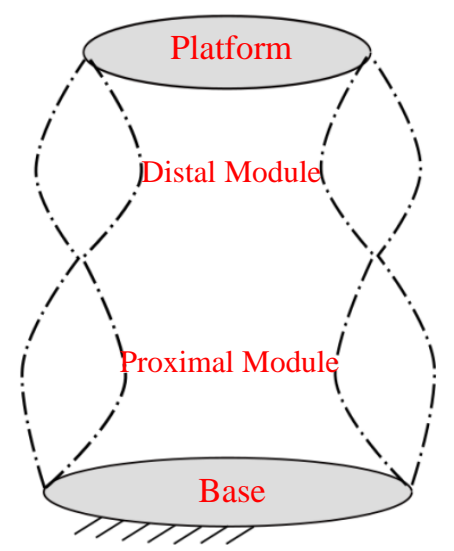

Figure 1: 2-dof Hybrid TPMs

\section{Two DOF Hybrid Translational Parallel Manipulators with Two Identical Legs.}

The general approach for the type synthesis of 2-dof hybrid TPMs with two identical legs is presented using the following procedure.

\section{Step 1: Classification of the Leg-Constraint Wrench System.}

The moving platform of the 2-dof hybrid TPMs is intended to perform two translational motions in the $\mathbf{x z}$-plane. In general configuration, the twist system of the moving platform amounts to $2 \xi_{\infty}-$ system and hence the order of the manipulator wrench system is $c=4$. The corresponding constraint wrench system is $1 \zeta_{0}-3 \zeta_{\infty}$-system, containing one zero-pitch wrench along $\mathbf{y}$-axis and three independent infinite-pitch wrenches, $\mathcal{W}^{c}=\operatorname{span}\left(\zeta_{0}, \zeta_{\infty 1}, \zeta_{\infty 2}, \zeta_{\infty 3}\right)$. Such manipulators can be obtained by a combination of two identical leg-constraint wrench system of order $c^{i}\left(0<c^{i} \leq 4\right)$, decomposed as follows:

- $c^{i}=4 \rightarrow 1 \zeta_{0}-3 \zeta_{\infty}$-system

- $c^{i}=3 \rightarrow 1 \zeta_{0}-2 \zeta_{\infty}$-system, $3 \zeta_{\infty}$-system

- $c^{i}=2 \rightarrow 1 \zeta_{0}-1 \zeta_{\infty}$-system, $2 \zeta_{\infty}$-system

- $c^{i}=1 \rightarrow 1 \zeta_{\infty}$-system, $1 \zeta_{0}$-system

Certain combinations cannot produce a complete manipulator constraint wrench system. Therefore, only three types of leg-constraint wrench systems can be used for the type synthesis of 2dof hybrid TPMs with two identical legs, namely:

- Type 1: $c^{i}=4 \rightarrow 1 \zeta_{0}-3 \zeta_{\infty}$-system, $\mathcal{W}^{c^{i}}=\operatorname{span}\left(\zeta_{0}, \zeta_{\infty 1}, \zeta_{\infty 2}, \zeta_{\infty 3}\right)$

- Type 2: $c^{i}=3 \rightarrow 1 \zeta_{0}-2 \zeta_{\infty}-$ system, $\mathcal{W}^{c^{i}}=\operatorname{span}\left(\zeta_{0}, \zeta_{\infty 1}, \zeta_{\infty 2}\right)$

- Type 3: $c^{i}=2 \rightarrow 1 \zeta_{0}-1 \zeta_{\infty}$-system, $\mathcal{W}^{c^{i}}=\operatorname{span}\left(\zeta_{0}, \zeta_{\infty}\right)$

Type 3 is included in this paper, since the combination of two legs with $1 \zeta_{0}-1 \zeta_{\infty}$-system can generate a manipulator with overall manipulator wrench system $1 \zeta_{0}-3 \zeta_{\infty}$-system. It occurs if and only if two $\zeta_{0}$ within two legs are always parallel. Two parallel $\zeta_{0}$ are able to generate $\zeta_{\infty}$ orthogonal to a plane containing the two parallel $\zeta_{0}$.

The overall twist system for one leg is determined by the linear combination of the twist systems associated with the proximal and distal modules as they are assembled in series. While the constraint wrench system for one leg is obtained by the intersection of constraint wrench systems associated with the proximal and distal modules. The constraint wrench systems associated with the proximal and distal modules are decomposed in the following. Note that these constraint wrench decompositions are interchangeable between proximal and distal modules. 
Type 1: $c^{i}=4 \rightarrow 1 \zeta_{0}-3 \zeta_{\infty}$-system

The leg-constraint wrench system of Type 1 is $1 \zeta_{0}-3 \zeta_{\infty}$-system $\left(c^{i}=4\right)$. Thus, the feasible constraint wrench systems for each module are:

Proximal module: $1 . c^{j}=5 \rightarrow 2 \zeta_{0}-3 \zeta_{\infty}$-system, $\mathcal{W}^{c^{j}}=\operatorname{span}\left(\zeta_{01}, \zeta_{02}, \zeta_{\infty 1}, \zeta_{\infty 2}, \zeta_{\infty 3}\right)$

2. $c^{j}=4 \rightarrow 1 \zeta_{0}-3 \zeta_{\infty}$-system, $\mathcal{W}^{c^{j}}=\operatorname{span}\left(\zeta_{0}, \zeta_{\infty 1}, \zeta_{\infty 2}, \zeta_{\infty 3}\right)$

Distal module: $\quad$ 1. $c^{j}=5 \rightarrow 2 \zeta_{0}-3 \zeta_{\infty}$-system, $\mathcal{W}^{c^{j}}=\operatorname{span}\left(\zeta_{01}, \zeta_{02}, \zeta_{\infty 1}, \zeta_{\infty 2}, \zeta_{\infty 3}\right)$

2. $c^{j}=4 \rightarrow 1 \zeta_{0}-3 \zeta_{\infty}$-system, $\mathcal{W}^{c^{j}}=\operatorname{span}\left(\zeta_{0}, \zeta_{\infty 1}, \zeta_{\infty 2}, \zeta_{\infty 3}\right)$

Type 2: $c^{i}=3 \rightarrow 1 \zeta_{0}-2 \zeta_{\infty}$-system

The leg-constraint wrench system of Type 2 is $1 \zeta_{0}-2 \zeta_{\infty}$-system $\left(c^{i}=3\right)$. Thus, the feasible constraint wrench systems for each module are:

Proximal module: $1 . c^{j}=5 \rightarrow 2 \zeta_{0}-3 \zeta_{\infty}$-system, $\mathcal{W}^{c^{j}}=\operatorname{span}\left(\zeta_{01}, \zeta_{02}, \zeta_{\infty 1}, \zeta_{\infty 2}, \zeta_{\infty 3}\right)$

2. $c^{j}=4 \rightarrow 1 \zeta_{0}-3 \zeta_{\infty}$-system, $\mathcal{W}^{c^{j}}=\operatorname{span}\left(\zeta_{0}, \zeta_{\infty 1}, \zeta_{\infty 2}, \zeta_{\infty 3}\right)$

3. $c^{j}=4 \rightarrow 2 \zeta_{0}-2 \zeta_{\infty}$-system, $\mathcal{W}^{c^{j}}=\operatorname{span}\left(\zeta_{01}, \zeta_{02}, \zeta_{\infty 1}, \zeta_{\infty 2}\right)$

4. $c^{j}=3 \rightarrow 1 \zeta_{0}-2 \zeta_{\infty}$-system, $\mathcal{W}^{c^{j}}=\operatorname{span}\left(\zeta_{0}, \zeta_{\infty 1}, \zeta_{\infty 2}\right)$

Distal module: $\quad$ 1. $c^{j}=4 \rightarrow 2 \zeta_{0}-2 \zeta_{\infty}$-system, $\mathcal{W}^{c^{j}}=\operatorname{span}\left(\zeta_{01}, \zeta_{02}, \zeta_{\infty 1}, \zeta_{\infty 2}\right)$

2. $c^{j}=3 \rightarrow 1 \zeta_{0}-2 \zeta_{\infty}$-system, $\mathcal{W}^{c^{j}}=\operatorname{span}\left(\zeta_{0}, \zeta_{\infty 1}, \zeta_{\infty 2}\right)$

Type 3: $c^{i}=2 \rightarrow 1 \zeta_{0}-1 \zeta_{\infty}$-system

The leg-constraint wrench system of Type 3 is $1 \zeta_{0}-1 \zeta_{\infty}$-system $\left(c^{i}=2\right)$. Thus, the feasible constraint wrench systems for each module are:

Proximal module: $1 . c^{j}=5 \rightarrow 2 \zeta_{0}-3 \zeta_{\infty}$-system, $\mathcal{W}^{c^{j}}=\operatorname{span}\left(\zeta_{01}, \zeta_{02}, \zeta_{\infty 1}, \zeta_{\infty 2}, \zeta_{\infty 3}\right)$

2. $c^{j}=4 \rightarrow 1 \zeta_{0}-3 \zeta_{\infty}$-system, $\mathcal{W}^{c^{j}}=\operatorname{span}\left(\zeta_{0}, \zeta_{\infty 1}, \zeta_{\infty 2}, \zeta_{\infty 3}\right)$

3. $c^{j}=4 \rightarrow 2 \zeta_{0}-2 \zeta_{\infty}$-system, $\mathcal{W}^{c^{j}}=\operatorname{span}\left(\zeta_{01}, \zeta_{02}, \zeta_{\infty 1}, \zeta_{\infty 2}\right)$

4. $c^{j}=3 \rightarrow 1 \zeta_{0}-2 \zeta_{\infty}$-system, $\mathcal{W}^{c^{j}}=\operatorname{span}\left(\zeta_{0}, \zeta_{\infty 1}, \zeta_{\infty 2}\right)$

5. $c^{j}=3 \rightarrow 2 \zeta_{0}-1 \zeta_{\infty}$-system, $\mathcal{W}^{c^{j}}=\operatorname{span}\left(\zeta_{01}, \zeta_{02}, \zeta_{\infty}\right)$

6. $c^{j}=2 \rightarrow 1 \zeta_{0}-1 \zeta_{\infty}$-system, $\mathcal{W}^{c^{j}}=\operatorname{span}\left(\zeta_{0}, \zeta_{\infty}\right)$

Distal module: $\quad$ 1. $c^{j}=3 \rightarrow 2 \zeta_{0}-1 \zeta_{\infty}$-system, $\mathcal{W}^{c^{j}}=\operatorname{span}\left(\zeta_{01}, \zeta_{02}, \zeta_{\infty}\right)$

2. $c^{j}=2 \rightarrow 1 \zeta_{0}-1 \zeta_{\infty}$-system, $\mathcal{W}^{c^{j}}=\operatorname{span}\left(\zeta_{0}, \zeta_{\infty}\right)$

\section{Step 2: Decomposition of the Constraint Wrench Systems for Proximal and Distal Modules.}

The next step for type synthesis of 2-dof hybrid TPMs is the decomposition of the constraint wrench systems for proximal and distal modules. It is noteworthy that the proximal and distal modules in Type 1, Type 2 and Type 3 have the following constraint wrench systems:

1. $c^{j}=5 \rightarrow 2 \zeta_{0}-3 \zeta_{\infty}$-system, $\mathcal{W}^{c^{j}}=\operatorname{span}\left(\zeta_{01}, \zeta_{02}, \zeta_{\infty 1}, \zeta_{\infty 2}, \zeta_{\infty 3}\right)$

2. $c^{j}=4 \rightarrow 1 \zeta_{0}-3 \zeta_{\infty}$-system, $\mathcal{W}^{c^{j}}=\operatorname{span}\left(\zeta_{0}, \zeta_{\infty 1}, \zeta_{\infty 2}, \zeta_{\infty 3}\right)$

3. $c^{j}=4 \rightarrow 2 \zeta_{0}-2 \zeta_{\infty}$-system, $\mathcal{W}^{c^{j}}=\operatorname{span}\left(\zeta_{01}, \zeta_{02}, \zeta_{\infty 1}, \zeta_{\infty 2}\right)$

4. $c^{j}=3 \rightarrow 1 \zeta_{0}-2 \zeta_{\infty}$-system, $\mathcal{W}^{c^{j}}=\operatorname{span}\left(\zeta_{0}, \zeta_{\infty 1}, \zeta_{\infty 2}\right)$

5. $c^{j}=3 \rightarrow 2 \zeta_{0}-1 \zeta_{\infty}$-system, $\mathcal{W}^{c^{j}}=\operatorname{span}\left(\zeta_{01}, \zeta_{02}, \zeta_{\infty}\right)$

6. $c^{j}=2 \rightarrow 1 \zeta_{0}-1 \zeta_{\infty}$-system, $\mathcal{W}^{c^{j}}=\operatorname{span}\left(\zeta_{0}, \zeta_{\infty}\right)$

Such module-constraint wrench systems emerge from the vector sum of the subleg-constraint wrench systems, due to the in-parallel arrangement of two identical sublegs.

\section{Step 3: Type Synthesis of Sublegs.}

Once the different combinations of subleg-constraint wrench systems are achieved, the kinematic chains that form the proximal and distal modules can be determined. The classification of screw systems [4] and the theory of virtual chain developed in [6] are used to generate the types of 
sublegs. In this section, a virtual chain is a serial kinematic chain associated with the motion pattern of the proximal modules or the distal modules. The number of joints in the subleg is obtained based on the mobility criterion written as: $f=F+\left(6-c^{k}\right)$, where $f$ is the number of 1-dof joints and $F$ is the mobility of a single-loop kinematic chain.

\section{Step 3a: Type Synthesis of Single-loop Kinematic Chains That Involve a Virtual Chain and have a Specified Subleg-Constraint Wrench System.}

This step deals with the determination of the number, type, and arrangement of joints in a subleg. The modules to be synthesized are composed of those sublegs and should contribute to one translational motion at least in the xz-plane. Accordingly, the virtual chain that is able to describe such a motion is P-virtual chain. The single-loop kinematic chain generating a specified motion pattern corresponding to the virtual chain is expressed as V-KC. Due to space limitation, the type synthesis is illustrated only for subleg of $1 \zeta_{0}-2 \zeta_{\infty}$-system, specifically the $3 \mathrm{~V}$-system (for futher detail of screw system, the reader can refer to [4]).

\section{Subleg of $1 \zeta_{0}-2 \zeta_{\infty}$-system, the $3 \mathrm{~V}$-system}

In the $3 \mathrm{~V}$-system, all planes that contain the constraint wrenches of infinite-pitch are parallel. All lines perpendicular to those planes contain the constraint wrenches of zero-pitch. This system defines a planar motion. The single-loop kinematic chains of $3 \mathrm{~V}$-system comprise four joints, including the P-virtual chain. Such a single-loop kinematic chain can be composed of three parallel $\mathrm{R}$ joints, as depicted in Fig. 2(a). The $\mathrm{P}$ joints may exist in the kinematic chain with its direction perpendicular to the axes of all $\mathrm{R}$ joints, as shown in Fig. 2(b) and 2(c).

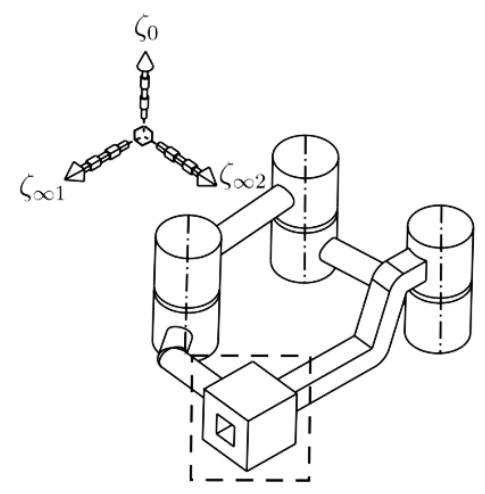

(a) $(R R R)_{E} V-K C$

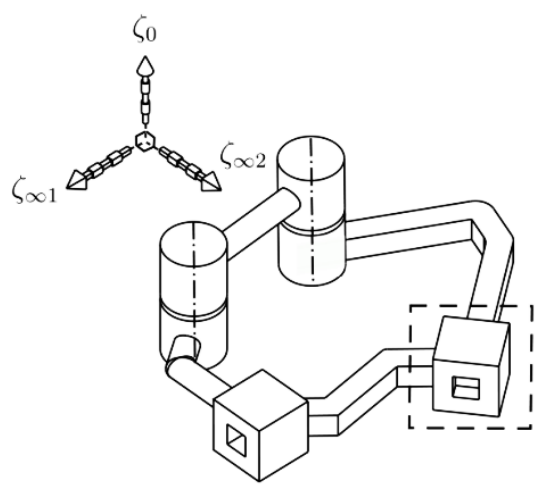

(b) $(P R R)_{E} V-K C$

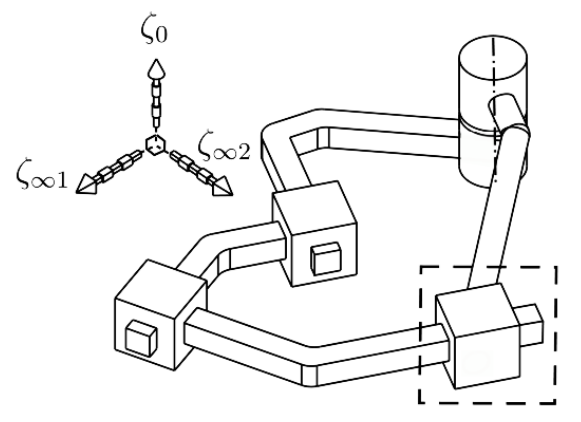

(c) $(P P R)_{E} V-K C$

(b) Figure 2: Sublegs associated with the $3 V$-system

\section{Step 3b: Generation Types of Sublegs.}

The sublegs are obtained by removing the P-virtual chain in the single-loop kinematic chains generated in Step 3a. For instance, by removing the P-virtual chain in (RRR) $\mathrm{E} V-\mathrm{KC}$ in Fig. 2(a), $(\mathrm{RRR})_{\mathrm{E}}$-Subleg is obtained. Table 1 gives all the types of sublegs that have been synthesized. All those sublegs can be assembled to generate either proximal or distal modules.

\section{Step 4: Assembly of Sublegs and Legs.}

The assembly process of 2-dof hybrid TPMs is performed for Type 1, Type 2 and Type 3. Each leg of manipulator is realized by mounting a proximal module and a distal module in series. Then, each leg becomes a hybrid manipulator and is attached to the base at one end and to the movingplatform at the other end. Therefore, the assembly process consists of two steps as explained thereafter. 
Table 1: Types of Sublegs for Proximal and Distal Modules

\begin{tabular}{|c|c|c|c|c|}
\hline$c^{k}$ & Subleg-constrai & wrench system & Subleg Types & Decription \\
\hline 5 & $2 \zeta_{0}-3 \zeta_{\infty}$-system & 5I-system & $\mathrm{P}$ & \\
\hline \multirow{5}{*}{4} & $1 \zeta_{0}-3 \zeta_{\infty}$-system & 4III-system & PP & All $\mathrm{P}$ are coplanar \\
\hline & \multirow{4}{*}{$2 \zeta_{0}-2 \zeta_{\infty}$-system } & \multirow{2}{*}{ 4II-system } & RR & All $\mathrm{R}$ are parallel \\
\hline & & & PR, RP & $\mathrm{P} \perp \mathrm{R}$ \\
\hline & & 4IV-system & PŔ, ŔP & $\begin{array}{l}\mathrm{P} \text { and } \mathrm{R} \text { are neither parallel nor } \\
\text { perpendicular }\end{array}$ \\
\hline & & 4V-system & $(\mathrm{PR})_{\mathrm{C}},(\mathrm{RP})_{\mathrm{C}}$ & $\mathrm{P} \| \mathrm{R}$ \\
\hline \multirow{12}{*}{3} & \multirow{6}{*}{$2 \zeta_{0}-1 \zeta_{\infty}$-system } & 3III-system & RPŔ, RPR & $\mathrm{R} \perp \mathrm{P}$ and $\mathrm{R} \perp \mathrm{P}$ \\
\hline & & 3IV-system & PRŔ, RPŔ, RŔP & $\begin{array}{l}\mathrm{R} \text { and } \mathrm{R} \text { intersect; and they are } \\
\text { perpendicular to } \mathrm{P}\end{array}$ \\
\hline & & \multirow{2}{*}{ 3VII-system } & PRŔ, RPŔ, RŔP & $\begin{array}{l}\mathrm{R} \text { and } \mathrm{R} \text { intersect; and they are neither } \\
\text { parallel nor perpendicular to } \mathrm{P}\end{array}$ \\
\hline & & & RPŔ, ŔPR & $\begin{array}{l}\mathrm{R} \text { and } \mathrm{R} \text { are skew; and they are neither } \\
\text { parallel nor perpendicular to } \mathrm{P}\end{array}$ \\
\hline & & \multirow{2}{*}{ 3VIII-system } & PRŔ, RPŔ, RŔP & $\begin{array}{l}\mathrm{R} \text { and } \mathrm{R} \text { intersect; and } \mathrm{P} \text { is parallel to } \\
\text { the plane containing both } \mathrm{R} \text { and } \mathrm{R}\end{array}$ \\
\hline & & & PRŔ, RPŔ, RŔP & $\begin{array}{l}\mathrm{R} \text { and } \mathrm{R} \text { are skew; and } \mathrm{P} \text { is parallel to } \\
\text { the plane containing both } \mathrm{R} \text { and } \mathrm{R}\end{array}$ \\
\hline & \multirow{6}{*}{$1 \zeta_{0}-2 \zeta_{\infty}$-system } & \multirow{3}{*}{ 3V-system } & $(\mathrm{RRR})_{\mathrm{E}}$ & All $\mathrm{R}$ are parallel \\
\hline & & & $(\mathrm{PRR})_{\mathrm{E}},(\mathrm{RPR})_{\mathrm{E}},(\mathrm{RRP})_{\mathrm{E}}$ & All $\mathrm{R}$ is parallel and perpendicular to $\mathrm{P}$ \\
\hline & & & $(\mathrm{PPR})_{\mathrm{E}},(\mathrm{PRP})_{\mathrm{E}},(\mathrm{RPP})_{\mathrm{E}}$ & All $\mathrm{P}$ is coplanar and perpendicular to $\mathrm{R}$ \\
\hline & & 3IX-system & PPR, PRP, RPP & $\begin{array}{l}\text { All } \mathrm{P} \text { are neither perpendicular nor } \\
\text { parallel to } \mathrm{R}\end{array}$ \\
\hline & & \multirow{2}{*}{ 3X-system } & PRR, RPR, RRP & $\mathrm{R} \| \mathrm{P}$ \\
\hline & & & PPR, RPP & $\mathrm{R}$ and $\mathrm{P}$ are parallel to the same plane. \\
\hline \multirow{12}{*}{2} & \multirow{7}{*}{$1 \zeta_{0}-1 \zeta_{\infty}$-system } & \multirow{4}{*}{ 2II-system } & Ŕ(RRR $)_{\mathrm{E}},(\mathrm{RRR})_{\mathrm{E}} \mathrm{R}^{\prime}$ & All $\mathrm{R}$ are parallel, except $\mathrm{R}$ \\
\hline & & & $\begin{array}{l}\text { RRŔŔ, ŔRRR, RŔŔR, } \\
\text { ŔRRŔ }\end{array}$ & \\
\hline & & & Ŕ(PRR $)_{\mathrm{E}},(\mathrm{PRR})_{\mathrm{E}} \dot{R}^{\prime}$ & \\
\hline & & & $\dot{\mathrm{R}}(\mathrm{PPR})_{\mathrm{E}},(\mathrm{PPR})_{\mathrm{E}} \mathrm{R}^{\prime}$ & \\
\hline & & 2IV-system & $\begin{array}{l}\text { PPRŔ, RŔPP, RPPŔ, } \\
\text { RPPR, PRŔP, PRRP, } \\
\text { PRPŔ, RPŔP }\end{array}$ & $\begin{array}{l}\text { All } \mathrm{P} \text { lie in the plane } \Pi_{1} \text {; all } \mathrm{R} \text { lie in the } \\
\text { plane } \Pi_{2} \text {. Both planes are neither } \\
\text { parallel nor perpendicular }\end{array}$ \\
\hline & & $2 \mathrm{~V}$-custem & $\begin{array}{l}\text { RRŘŘ, ŘŘRR, RŘŘR, } \\
\text { ŘRR }\end{array}$ & $\mathrm{R}$ and $\check{\mathrm{R}}$ are parallel to the same plane \\
\hline & & 2V-system & $\begin{array}{l}\text { PPRŘ, RŘPP, PRŘP, } \\
\text { RPPŘ }\end{array}$ & Each $R$ is parallel to each $P$ \\
\hline & & $2 \mathrm{C}$ sistom & ŔRŘ̌ & \\
\hline & & Zu-system & PRŔŘ, ŔŘPR & \\
\hline & $2 \zeta_{0}$-system & & Ŕ(RRR $)_{S},(R R R)_{S} R^{\prime}$ & \\
\hline & & 2I-system & $\mathrm{P}(\mathrm{RRR})_{\mathrm{S}},(\mathrm{RRR})_{\mathrm{S}} \mathrm{P}$ & \\
\hline & & & 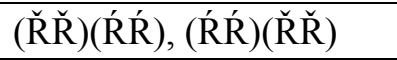 & \\
\hline & & & $(\mathrm{RRR})_{\mathrm{E}} \check{\mathrm{R} R}, \check{\mathrm{R}} \mathrm{R}(\mathrm{RRR})_{\mathrm{E}}$ & \\
\hline & & & $(\mathrm{RRR})_{\mathrm{S}} \mathrm{R} R$, ŔŔ(RRR) $)_{\mathrm{S}}$ & \\
\hline 1 & $1 \zeta_{0}$-system & 1-system & $(\mathrm{RRR})_{\mathrm{S}} \check{\mathrm{R} R}, \check{\mathrm{R}} \mathrm{R}(\mathrm{RRR})_{\mathrm{S}}$ & \\
\hline & & & $(\mathrm{RRR})_{\mathrm{S}} \mathrm{R} P, \mathrm{R}^{\mathrm{R}}(\mathrm{RRR})_{\mathrm{S}}$ & \\
\hline & & & $(\mathrm{RRR})_{\mathrm{S}} \mathrm{PP}, \mathrm{PP}(\mathrm{RRR})_{\mathrm{S}}$ & \\
\hline
\end{tabular}




\section{Step 4a: Assembly of Sublegs $\rightarrow$ Proximal and Distal Modules.}

The proximal and distal modules can be obtained by assembling sublegs from Tab. 1 . Nevertheless, the following conditions should be respected:

1. The overall constraint wrench system of a module should constitute the desired constraint wrench system, as explained in Step 1.

2. At least one translational twist generated by the module should lie in $\mathbf{x z}$-plane.

\section{Step 4b: Assembly of Legs $\rightarrow$ 2-dof Hybrid Translational Parallel Manipulators.}

The legs of the 2-dof hybrid TPMs are synthesized by mounting the proximal and distal modules in series. However, the following conditions should be fulfilled:

1. The leg-constraint wrench system for Type 1, Type 2, and Type 3 should be $1 \zeta_{0}-3 \zeta_{\infty}$-system, $1 \zeta_{0}-2 \zeta_{\infty}$-system, and $1 \zeta_{0}-1 \zeta_{\infty}$-system, respectively.

2 . The linear combination of the leg-constraint wrench system should be $1 \zeta_{0}-3 \zeta_{\infty}$-system.

Figure 3 illustrates a novel 2-dof hybrid TPM with two identical legs. This is a Type 1 mechanism that has been synthesized with the proposed approach. Each leg has $1 \zeta_{0}-3 \zeta_{\infty}$-system that is composed of one proximal module and one distal module. Both proximal and distal modules are

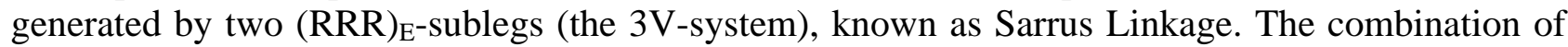
these sublegs produces the distal-constraint wrench system: $2 \zeta_{0}-3 \zeta_{\infty}$-system. This manipulator is named Q-Sarrus, Q standing for Quadruple.

Figure 4 depicts a manipulator of Type 2 which is synthesized with the proposed method. This mechanism is named IRSBot-2 [3]. Its proximal modules have a $2 \zeta_{0}-3 \zeta_{\infty}$-system and are made up of $\Pi$-joint. Its distal modules have $2 \zeta_{0}-2 \zeta_{\infty}$-system and are composed of 2-UU kinematic chains.

Figure 5 shows a 2-dof hybrid TPM of Type 3. The architecture of this mechanism was synthesized with the proposed approach. The proximal modules have a $2 \zeta_{0}-3 \zeta_{\infty}$-system and are composed of two RR-sublegs, as П-joint. The distal modules of this type have $2 \zeta_{0}-1 \zeta_{\infty}$-system. It is generated by two identical CPR-sublegs having $1 \zeta_{0^{-}} 1 \zeta_{\infty}$-system (2IV-system) as its constraint wrench system.

\section{Step 5: Selection of the Actuated Joints}

At this stage, let us consider the condition on the constraint wrench system is satisfied, namely, the assembly of legs applies a $1 \zeta_{0}-3 \zeta_{\infty}$-system on the moving platform. In a general configuration, the system spanned by the constraint wrench system, $\mathcal{W}^{c}$, and the actuation wrench system, $\mathcal{W}^{a}$, should make a 6-system. Ultimately, the selection of the actuated joints for 2-dof hybrid TPMs can be made in such way that a basis of the actuation wrench system contains at least two actuation forces.

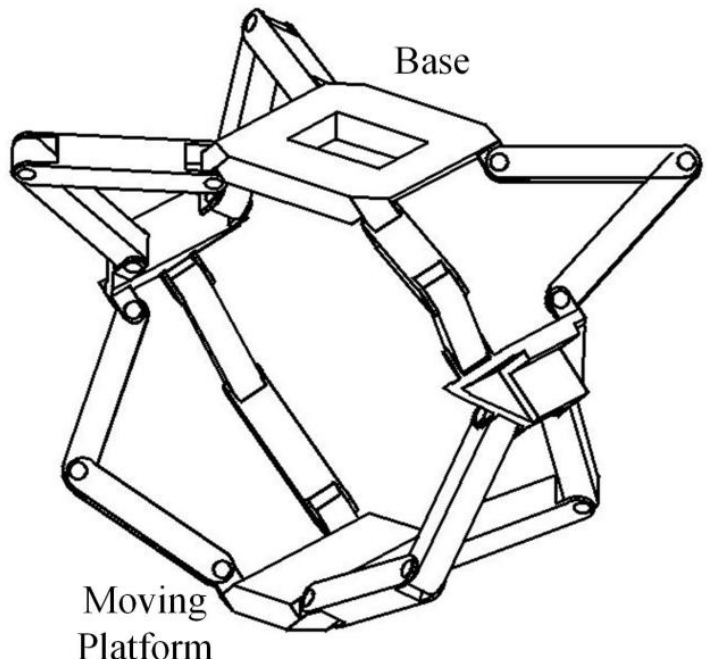

Figure 3: Type 1, Q-Sarrus

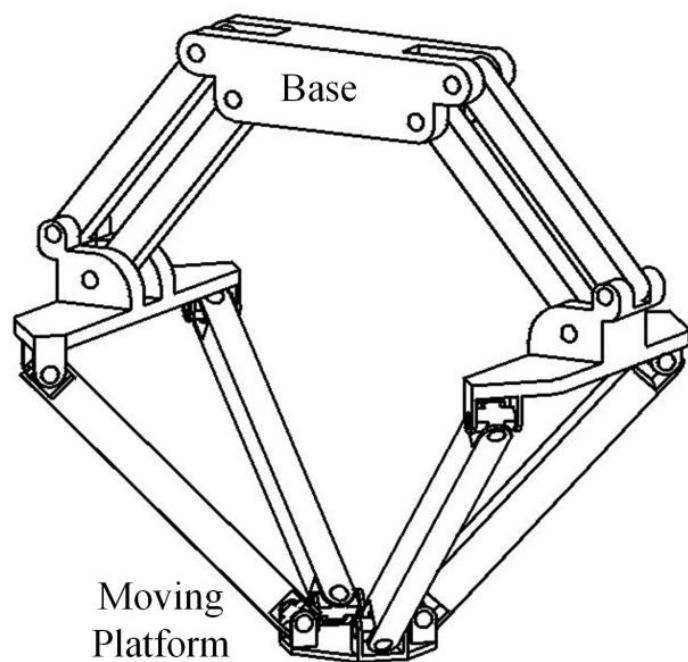

Figure 4: Type 2, IRSBot-2 


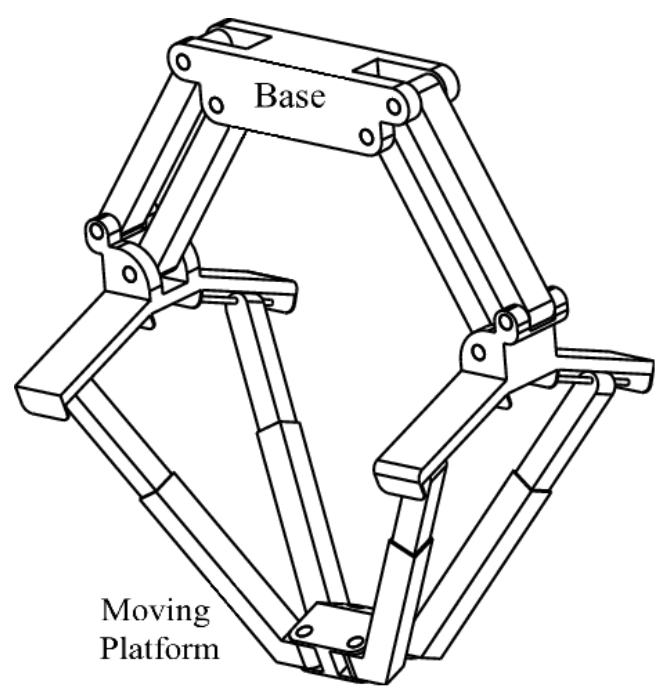

Figure 5: Type 3, 2-П(2-CPR)

\section{Conclusions}

A general approach has been introduced in this paper for the type synthesis of 2-dof hybrid TPMs with identical legs. The proposed approach is based on the screw theory and the virtual chain method described in [6]. Three types of 2-dof hybrid TPMs have been highlighted with regard to the wrench system associated with their legs, namely Type 1: $1 \zeta_{0}-3 \zeta_{\infty}$-system, Type $2: 1 \zeta_{0}-2 \zeta_{\infty}$-system, and Type 3: $1 \zeta_{0}-2 \zeta_{\infty}$-system. Moreover, many novel 2-dof hybrid TPMs have been obtained and three of them have been illustrated, namely, the Q-Sarrus (Type 1), the IRSBot-2 (Type 2), and the 2-П(2-CPR) (Type 3).

\section{References}

[1] Gao, F., Li, W., Zhao, X., Jin, Z., and Zhao, H., New Kinematic Structure for 2-, 3-, 4-, and 5DOF Parallel Manipulator Designs, Mechanism and Machine Theory, 37(11), pp. 1395-1411, 2002.

[2] Company, O., Pierrot, F., Krut, S., Baradat, C., and Nabat., V, Par2: a Spatial Mechanism for Fast Planar Two-Degree-of-Freedom Pick-and-Place Applications, Mecanica, 46(1), pp. 239248, 2011.

[3] Germain, C., Caro, S., Briot, S., and Wenger, P., Singularity-free design of the translational parallel manipulator IRSBot-2, Mechanism and Machine Theory, 64, pp. 262-285, 2013.

[4] K. H. Hunt., Geometry of Mechanics, Clarendon Press Oxford, Oxford, United Kingdom. pp. 331-368, 1978

[5] Carricato, M., Persistent Screw Systems of Dimension Four, In Springer (ed.) The $13^{\text {th }}$ International Symposium on Advances in Robot Kinematics, pp. 147-156, 2012.

[6] Kong, X., and Gosselin, C., Type Synthesis of Parallel Mechanism, Springer, Germany, 2007. 